\title{
Investigation of Reinforced Concrete Column Containing Metakaolin and Fly Ash Cementitious Materials
}

\author{
R. Dharmaraj $\mathbb{D}^{1},{ }^{1}$ Sudhir Singh Bhadauria, ${ }^{2}$ K. Mayilsamy, ${ }^{3}$ J. Thivya, ${ }^{3}$ Alagar Karthick (iD), \\ I. Baranilingesan, ${ }^{4}$ V. Mohanavel $\mathbb{D}^{5}{ }^{5}$ M. Muhibbullah $\mathbb{D}^{6},{ }^{6}$ and Sameh M. Osman ${ }^{7}$ \\ ${ }^{1}$ Department of Civil Engineering, KPR Institute of Engineering \& Technology, Coimbatore 641407, India \\ ${ }^{2}$ University Institute of Technology, Rajiv Gandhi Proudyogiki Vishwavidyalaya, Bhopal 462033, Madhya Pradesh, India \\ ${ }^{3}$ Department of Civil Engineering, University College of Engineering, Dindigul 624622, Tamil Nadu, India \\ ${ }^{4}$ Renewable Energy Lab, Department of Electrical and Electronics Engineering, KPR Institute of Engineering and Technology, \\ Coimbatore 641407, Tamil Nadu, India \\ ${ }^{5}$ Centre for Materials Engineering and Regenerative Medicine, Bharath Institute of Higher Education and Research, \\ Chennai 600073, Tamil Nadu, India \\ ${ }^{6}$ Department of Electrical and Electronic Engineering, Bangladesh University, Dhaka 1207, Bangladesh \\ ${ }^{7}$ Chemistry Department, College of Science, King Saud University, P.O. Box 2455, Riyadh 11451, Saudi Arabia \\ Correspondence should be addressed to R. Dharmaraj; dr.r.dharmaraaj@gmail.com
}

Received 10 October 2021; Revised 3 February 2022; Accepted 4 February 2022; Published 28 February 2022

Academic Editor: Flavio Stochino

Copyright ( 2022 R. Dharmaraj et al. This is an open access article distributed under the Creative Commons Attribution License, which permits unrestricted use, distribution, and reproduction in any medium, provided the original work is properly cited.

\begin{abstract}
Nowadays, high-performance concrete is employed in the building sector all over the world. For a strong and durable construction, high performance appears to be a better option. These specially designed types of concrete are made using both conventional and unique materials to fulfill a combination of performance requirements. The objective of this experiment is to investigate the behaviour of short and long columns made of high-performance concrete (HPC). In this study, HPC was manufactured by essential denominators such as cement, fine aggregate, coarse aggregate, water, and mineral admixtures such as metakaolin and fly ash at different replacement levels. The high-performance concrete (HPC) was designed with compressive strength (CS) of about $60 \mathrm{~N} / \mathrm{mm}^{2}$. The mixture was developed under the guidelines in modified ACI 211.4R-93. All combinations have the same 0.30 water binder ratio $(\mathrm{W} / \mathrm{B})$ and are utilized to achieve improved workability with the addition of a superplasticizer for a chemical admixture, namely, CERAPLAST 300. Seven proportions are cast with $0 \%, 5 \%, 7.5 \%$, and $10 \%$ replacement of cement with metakaolin and another set of specimens with $5 \%, 7.5 \%$, and $10 \%$ replacement with metakaolin along with a constant $10 \%$ replacement of fly ash. For the investigation of strength properties, specimens (cube, prism, and cylinders) such as compressive strength (CS) (3, 7, 28, 56, and 90 days), flexural (FS) and tensile strength (STS) (28 days) and modulus of elasticity were cast ( 28 days). Totally 14 columns, 7 for short and long columns, were cast, each cured for 28 days. These specimens have been tested in the $1000 \mathrm{kN}$ loading frame. All small columns were tested with concentrated compression, whereas long columns were investigated with little concentration and uniaxial bending. The compressive strength of HPC with 7.5 percent metakaolin and 10 percentage fly ash (MR6) is $59 \mathrm{MPa}, 7.34 \%$ greater than the compressive strength of reference concrete.
\end{abstract}

\section{Introduction}

High-performance concrete is a word that refers to concrete that has unique qualities. In the beginning, the HPC was classified as high-strength, structural concrete [1]. Advances in concrete technology have made a new mix design that is well mixed, which is well mixed, conveyed, located, consolidated, and cured to ensure good performance, like high compressive strength, high density, low shrinkage, high elasticity module, and low permeability [2].

Concrete that meets specific performance and homogeneity standards that cannot always be met with standard components and mixing, pouring, and curing procedures. Enhancements to the following may be required to meet 
these requirements: long-term mechanical characteristics, simple fabrication and completion without separation, earlyage strength, toughness, volume stability, and long-term survival in the hostile environment $[3,4]$.

In a nutshell, HPC is just concrete that is supposed to perform better in a particular application. That application may or may not necessitate a greater compressive strength. Note that, unlike the performance concrete observed in today's standards, the concrete producer is not always solely responsible for proportioning an HPC to improve performance [5].

In the recent two decades, high-performance concrete (HPC) development and utilization have increased significantly. Any concrete that meets specific requirements suggested by conventional cement concrete (CCC) may be highperformance concrete. In the synthesis of HPC, compounds play an essential role [6]. Mineral and chemical admixtures developments have allowed the production of concrete with comparatively high strength. In many countries, concrete between 90 and $112 \mathrm{MPa}$ is now commercially manufactured and utilized in the building sector. Several researchers have been working with various mineral admixtures such as fly ash (FA), metakaolin (MK), silica fume (SF), pulverized fuel ash (PFA), and GGBS in the production of HPC. The quest for alternative mineral admixtures to improve cementitious characteristics and attain high compressive and flexural strength is constantly continuous $[7,8]$.

HPC may be tailored to fulfill particular performance criteria in terms of workability, mechanical properties, and durability studies. In addition to the materials commonly used for regular concrete, superplasticating chemical admixtures are essential to make HPC. However, such HPC necessitates a huge paste volume, which frequently results in excessive shrinkage and a considerable heat of hydration evolution, as well as a cost increase. Partial substitution of cement is generally done using cementitious materials such as metakaolin, SF, FA, and GGBS. Furthermore, to improve the qualities of fresh concrete, these materials also increase their durability. The use of microsilica is essential when a high degree of resistance is needed, especially in precast constructional parts, as microsilica, even at 12 and 24 hours, reaches an early strength. Furthermore, it enhances impermeability, aggressive fluid resistance, alkaline aggregate reaction mitigations, and other properties $[9,10]$.

High-strength and HPC have been used for many years in the columns of high-rise structures $[11,12]$. However, HPC has become more popular in recent years in bridges where both strength and durability are significant parameters. A more affordable product is produced; a viable technical solution or a mix of the two is the primary rationale for adopting HPC $[13,14]$. Nowadays, an HPC cubic yard typically costs more than a regular cubic yard. To confirm that the concrete reaches its specific performance, the HPC requires an additional quantity of products such as cement, fly ash, metakaolin, silica fume, water reduction, and retardants. Concrete is nevertheless only one part of the construction, and the entire cost of a finished project is more than the cost of a single material $[15,16]$. HPC, on the other hand, should not be specified if there are no economic or technological benefits to be achieved from its utilization [17].

For many years, the economic consequences of highstrength HPC have been recognized in the columns of multistory structures. High-strength concrete (HSC) is the most cost-effective means of carrying a vertical load to the foundation [18, 19]. Concrete, steel reinforcement, and formwork constitute the three principal components contributing to the column cost. The column size is decreased by the use of high-strength concrete. Therefore, it requires less concrete and less formwork. At the same time, a minimum quantity permitted by the code might be decreased to the amount of vertical reinforcement. Consequently, the least economical column is obtained with the shortest size column, the least amount of reinforcement, and the maximum easily accessible concrete strength [20].

Cementitious materials have been used in construction from the time of the Babylonians, Romans, and Egyptians. Throughout the ages and the last four decades, these materials have undergone several modifications. A process and manufacturing changes have revealed that cement and concrete composites are currently the most affordable building materials [21].

Despite this progress, it was necessary to enhance the durability elements of the concrete mixers, particularly in the coastal areas and in industries with harsh conditions. As a first stage, the decreased $\mathrm{w} / \mathrm{c}$ ratio results in HSC. This can better withstand the damage to the environment [22, 23]. However, the demands for workability hampered first attempts in this area until superplasticizers or water reducers of high quality had been produced. By allowing for higher cement content, these ingredients made it possible to produce HSC with a low w/c ratio [24, 25]. However, it was quickly discovered that improving performance levels needed higher cement content, making the concrete considerably more environment-friendly. As a result of these considerations, minimum and maximum cement content limits were established for various settings [26, 27].

Moreover, it was recognized that high strength alone is not an efficient way of attaining high performance. The endurance of these ingredients in different settings necessitates detailed research to find a suitable alternative $[28,29]$. This involved the use of industrial effluents with pozzolanic concrete characteristics, as well as the prospect of achieving durability enhancements in addition to the achievement of HSC composites [30-32]. With pozzolanic materials and superplasticizers, it is now possible to combine both high strength and excellent performance in concrete composites.

In this investigation, metakaolin and fly ash were used to substitute Portland cement in the interval of $0-10 \%$ by weight of cement. When compared to reference concrete, the findings of fresh and hardened concrete characteristics suggest that using metakaolin and fly ash in HPC needs a superplasticizer. The results also show that metakaolin and fly ash may produce cost-effective HPC with 28-day strength up to $64 \mathrm{MPa}$. These types of concrete can be utilized for a variety of purposes, including cast-in-place and precast concrete construction. 


\section{Experimental Method}

\subsection{Materials}

2.1.1. Cement. The current experiment makes use of 43grade ordinary Portland cement [33]. Cement characteristics are evaluated following IS 4031-1968, and the specific gravity (Sp.G), consistency of cement (CC), initial setting time (IST), and final setting time (FST) are mentioned in Table 1.

2.1.2. Metakaolin. Metakaolin is a new supplementary cementitious material that meets ASTM C 618's Class N pozzolan standard. The use of metakaolin as an additive in concrete has been the focus of just a few investigations. Metakaolin is a calcined clay that is purer [34]. It has high reactivity and is typically free of contaminants due to the increased presence of amorphous aluminosilicates. English Indian Clays Limited, Thiruvananthapuram, Kerala, India, provided the material. Table 1 lists metakaolin chemical properties. The metakaolin sample "Metacon Metakaolin" used in this study is shown in Figure 1.

2.1.3. Fly Ash. At the Mettur Thermal Power Plant, Class F fly ash is gathered. The features of the fly ash are shown in Table 1. The fly ash sample is displayed in Figure 2.

2.1.4. Fine Aggregate ( $F A)$. The fine aggregate was the sand of the river. Table 2 lists the characteristics of the fine aggregates.

2.1.5. Coarse Aggregate (CA). Experiments were done to find the Sp.G and fineness of the CA applied in this research as per IS 2386-1983, and the characteristics of the CA are presented in Table 2.

2.1.6. Water. Water should be used for concrete preparation if appropriate for drinking. Water should be clean and free of pollutants such as tar, alkali, and acids. The additional amount of water should be the minimal chemical reaction required for unhydrated cement; following the Neville report, cement paste would be defective only when excessive water is present, causing its hardening to result in excessive voids. In the current study, mixing and cure of concrete cubes were utilized for drinking water.

2.1.7. Superplasticizer. This investigation has been carried out using a superplasticizer (CERAPLAST 300) [33]. These parameters describe the superplasticizer in Table 3.

2.1.8. Mix Design. For the proportioning of concrete mix M60, an ACI mix design is utilized $[35,36]$. Mix proportioning details are shown in Table 4.

As per ACI 2114R-1993, the mix proportion design is adopted. This code offers a technique for selecting the HSC mix ratio and optimizes this mixture ratio based on the test lots. The approach is confined to the creation of high-performance concrete utilizing standard materials and procedures of production (Table 4).
TABle 1: Physicochemical properties of cement, metakaolin, and fly ash.

\begin{tabular}{lccc}
\hline Properties/composition & Cement & Metakaolin & Fly ash \\
\hline Physical properties & & & \\
Sp.G & 3.15 & 2.50 & 2.15 \\
$\mathrm{CC}$ & $29 \%$ & - & - \\
$\mathrm{IST}$ & 30 minutes & - & - \\
$\mathrm{FST}$ & 10 hours & - & - \\
& Powder & Powder form & Powder \\
Physical appearance & form & - & form \\
Class & - & - & \\
Chemical composition & & & \\
$(\%)$ & & 55.70 & 59.73 \\
$\mathrm{SiO}_{2}$ & 20.27 & 38.60 & 30.18 \\
$\mathrm{Al}_{2} \mathrm{O}_{3}$ & 5.32 & 2.03 & 2.80 \\
$\mathrm{Fe}_{2} \mathrm{O}_{3}$ & 3.56 & 0.20 & 0.73 \\
$\mathrm{CaO}^{\mathrm{MgO}}$ & 60.41 & 0.32 & 0.83 \\
$\mathrm{MgO}$ & 2.46 & & \\
\end{tabular}

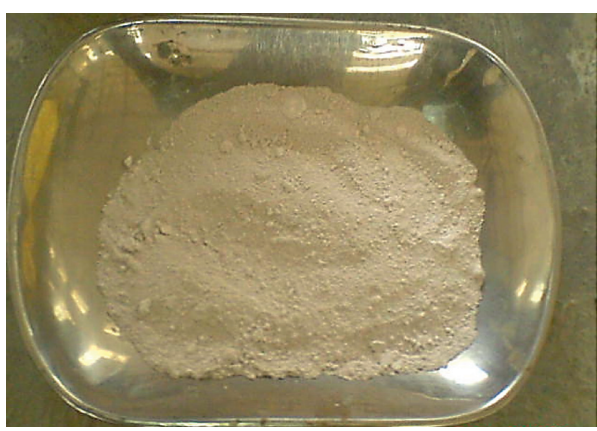

Figure 1: Metakaolin sample.

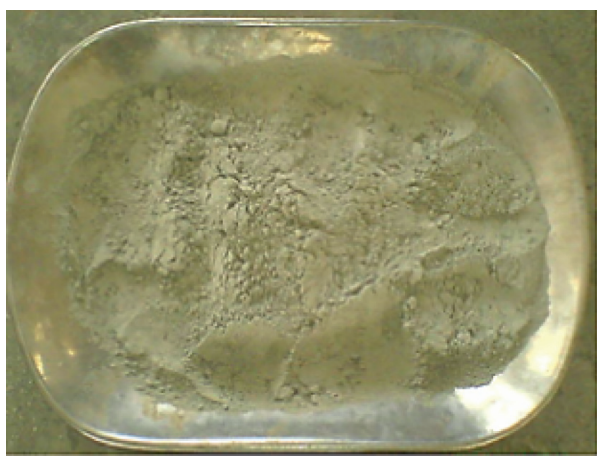

FIgURE 2: Fly ash sample.

TABLE 2: Basic properties of aggregates.

\begin{tabular}{lcc}
\hline Properties & Fine aggregate & $\begin{array}{c}\text { Coarse } \\
\text { aggregate }\end{array}$ \\
\hline Size & Passing through a $4.75 \mathrm{~mm}$ sieve & $20 \mathrm{~mm}$ \\
Specific gravity & 2.65 & 2.78 \\
Bulk density & $1731 \mathrm{~kg} / \mathrm{m}^{3}$ & $1682 \mathrm{~kg} / \mathrm{m}^{3}$ \\
Fineness & 2.28 & 6.32 \\
\hline
\end{tabular}


TABLE 3: Characteristics of superplasticizer.

\begin{tabular}{lc}
\hline Parameter & Analysis \\
\hline Sp.G & 1.23 \\
Air-entrainment & $1 \%$ (max.) \\
$\mathrm{Cl}$ content & $\mathrm{Nil}$ \\
$\mathrm{NO}_{3}$ content & $\mathrm{Nil}$ \\
$\mathrm{Solid}$ contents & 0.48 \\
Supply form & Liquid \\
Color & Dark brown \\
\hline
\end{tabular}

2.1.9. Mix Proportion Details. The concrete utilized in this investigation had a strength of $60 \mathrm{MPa}$. The M60 design was based on the ACI committee's recommendation. The mixes MR1, MR2, MR3, and MR4 were made by replacing 0, 5, 7.5, and $10 \%$ of the weight of cement with metakaolin, respectively, while the mixes MR5, MR6, and MR7 were made by substituting the weight of cement with the above percent of metakaolin and $10 \%$ of FA. The W/B is estimated to be 0.30 . Table 5 contains a description of the mixes utilized in this investigation.

2.2. Experimental Setup. In the combinations MR1, MR2, MR3, MR4, MR5, MR6, and MR7, metakaolin was used to replace $0,5,7.5$, and $10 \%$ of the weight of cement. For all mixtures, the $\mathrm{W} / \mathrm{B}$ was kept at 0.30 . Superplasticizer is the chemical admixture utilized in the project CERAPLAST 300. Steel moulds were used to cast all of the concrete samples. Before casting HPC specimens, machine oil was sprayed on the mould. During the concrete process, all ingredients are mixed thoroughly, poured, and compacted. The concrete samples were poured into the mould after 24 hours, and specimens were cured [37]. The CS test was made on cube samples. Prisms were utilized to evaluate FS, while cylinders were used to examine STS. Table 6 depicts the concrete test characteristics and specimen shapes. An experimental program envisioned in Figure 3 is shown schematically.

\subsection{Mechanical Properties of Hardened Concrete}

2.3.1. Testing of Specimens. The concrete specimen's strength was evaluated by testing. Before the test, the samples were withdrawn from the water for appropriate cure periods, and several tests were done according to IS requirements.

2.3.2. Compressive Strength Test. Most essential concrete and structural application characteristics are directly connected to CS, and the CS test is the foremost generally used [37]. A CTM was used to carry out the test according to IS 516-1959 standards. Equation (1) is used to calculate the CS of a concrete cube:

$$
\text { cmpressive strength }=\frac{\text { maximum load }}{C / S \text { area of the cube }} \frac{\mathrm{N}}{\mathrm{mm}^{2}} .
$$

2.3.3. Split Tensile Strength Test. To evaluate the STS, the cylinders $(100 \times 200 \mathrm{~mm})$ were cast. Tests were conducted on different concrete combinations MR1 to MR7 conferring to IS 5816-1970 for the split tensile strength. The experiment was performed in CTM of $2000 \mathrm{kN}$ capacity. The cylinders are computed with equation (2) for tensile strength [37, 38]. Cylinder failure is seen in Figure 4.

$$
\text { Split tensile strength }=\frac{2 P}{\pi L D},
$$

where $P$ denotes load, $\mathrm{kN}, L$ denotes length, $\mathrm{mm}$, and $D$ denotes diameter, $\mathrm{mm}$.

2.3.4. Flexural Strength Test. For the FS test, a two-point test was carried out in the $400 \mathrm{KN}$ universal test machine. In the bottom fibre of the test beam, the maximum stress potentially reached is known as the Modulus of Rupture. At twopoint load, the maximum stress is positioned on $1 / 3$ of the distance of the extreme fibres for this crucial crack to occur in any part in a mid-third of the prism length [37]. The test setup is illustrated in Figure 5. To evaluate the flexural strength of various concrete combinations, tests were conducted according to IS 5816-1970. The flexural strength of a concrete prism is calculated using (3).

In the following formula, the flexural strength is obtained:

$$
\begin{aligned}
& \text { flexural stress }=\frac{P L}{b d^{2}} \text { for } a>13.3 \mathrm{~cm}, \\
& \text { flexural stress }=\frac{3 P a}{b d^{2}} \text { for } a<13.3 \mathrm{~cm},
\end{aligned}
$$

where $P$ denotes load, $\mathrm{kN}, L$ denotes length, $\mathrm{mm}, d$ denotes depth, $\mathrm{mm}, a$ denotes distance of the crack from the nearest support.

\subsection{Durability Studies}

2.4.1. Water Absorption. The water absorption of HPC samples was defined using the ASTMC-642 method. The concrete cube measured $100 \times 100 \times 100 \mathrm{~mm}$ in dimension. A concrete cube represented each proportion of the mix. The wet weights of the specimens were obtained after 28 days of curing, and the concrete specimens were then placed in an oven at 105 degrees Celsius for 24 hours. The concrete sample was taken down from the oven after 24 hours, ovendried concrete specimen was ventilated to room temperature, and the dry weights of the sample were collected. The specimen was submerged in water for another 24 hours. The wet weight was measured after 24 hours. The percentage of water absorption is calculated as the difference between the specimen's wet and dry weight [39]. When the percentages of metakaolin and fly ash are increased, the water absorption decreases. The MR7 concrete mix absorbs the least amount of water-related towards the reference concrete mix. Equation (4) is used to calculate the water absorption of a concrete cube. 
TABLE 4: Mix proportion details $\left(\mathrm{kg} / \mathrm{m}^{3}\right)$.

\begin{tabular}{lccccccc}
\hline Mix ratio & Cement & MK & FA & Fine aggregate & Coarse aggregate & Superplasticizer & W/B \\
\hline MR1 & 571.91 & 0 & 0 & 609.72 & 1171.80 & $6.97(1.50)$ & 0.30 \\
MR2 & 543.31 & 28.60 & 0 & 603.42 & 1171.80 & 1171.80 & $0.83(1.90)$ \\
MR3 & 529.01 & 42.89 & 0 & 600.27 & 1171.80 & $9.30(2.00)$ \\
MR4 & 514.72 & 57.19 & 0 & 597.12 & 1171.80 & $9.76(2.10)$ \\
MR5 & 486.12 & 28.60 & 57.19 & 580.87 & 1171.80 & $16.83(3.60)$ & 0.30 \\
MR6 & 471.82 & 42.89 & 57.19 & 577.72 & 1171.80 & 0.30 \\
MR7 & 457.53 & 57.19 & 57.19 & 574.57 & $17.20(3.70)$ & 0.30 \\
\hline
\end{tabular}

TABLE 5: Description of mix proportion details.

\begin{tabular}{lccr}
\hline Specimen's name (mix) & \% of MK & \% of FA & Mix ratio \\
\hline MR1 & 0 & 0 & $1: 1.07: 2.05: 0.3$ \\
MR2 & 5 & 0 & $1: 1.06: 2.05: 0.3$ \\
MR3 & 7.5 & 0 & $1: 1.05: 2.05: 0.3$ \\
MR4 & 10 & 0 & $1: 1.04: 2.05: 0.3$ \\
MR5 & 5 & 10 & $1: 1.02: 2.05: 0.3$ \\
MR6 & 7.5 & 10 & $1: 1.01: 2.05: 0.3$ \\
MR7 & 10 & 10 & $1: 1.00: 2.05: 0.3$ \\
\hline
\end{tabular}

TABle 6: Tests and specimen sizes.

\begin{tabular}{lcccc}
\hline Properties & Specimen & Properties studied & Number of samples & Specimens sizes \\
\hline & Cube & Compressive strength & $7 \times 15=105$ & $100 \mathrm{~mm} \times 100 \mathrm{~mm} \times 100 \mathrm{~mm}$ \\
Concrete strength-related properties & Prism & Flexural strength & $7 \times 2=14$ & $100 \mathrm{~mm} \times 100 \mathrm{~mm} \times 500 \mathrm{~mm}$ \\
& Cylinder & Split tensile strength & $7 \times 2=14$ & $100 \mathrm{~mm} \times 200 \mathrm{~mm}$ \\
\hline Durability studies & Cube & Water absorption & $7 \times 2=14$ & $100 \mathrm{~mm} \times 100 \mathrm{~mm} \times 100 \mathrm{~mm}$ \\
Test on short columns & Square & Axial behaviour & $1 \times 7=7$ & $100 \mathrm{~mm} \times 100 \mathrm{~mm} \times 1000 \mathrm{~mm}$ \\
Test on long columns & Square & Axial behaviour & $1 \times 7=7$ & $100 \mathrm{~mm} \times 100 \mathrm{~mm} \times 1500 \mathrm{~mm}$ \\
\hline
\end{tabular}

Water Absorption $=\frac{\text { wet weight }- \text { dry weight }}{\text { dry weight }} X 100 \%$.

\subsection{Design of Columns}

2.5.1. Compression Member. Effective length is more than three times the length of its least lateral dimension. These are ubiquitous components found in most buildings that transfer loads from floors and beams to the foundation $[40,41]$. The columns in industrial buildings are subjected not only to high compression but also to reasonably large bending moment about either the $x$ - or $y$-axis only, and it is classified as follows:
(i) Axial loaded column
(ii) Uniaxial bending in an axial load column
(iii) Biaxial bending in an axial load column

A column of intermediate length $(1 / d \leq 12)$ is called a short column, and the one which is relatively long concerning its least lateral dimension $d$ is called the long or slender column $(1 / d \geq 12)$. A long column is susceptible to buckling and has to be designed carefully. The slenderness ratio $1 / d$ in any case should be restricted to 60 . As the columns are under primary compression, the failure is usually sudden, with a warning given through the spalling of the cover.
The ultimate load is not decreased by bending deformations at a short column since the excess eccentricities are either insignificant or absent in the critical section.

A long column is a column in which an amplified bending moment induced with more eccentricities reduces the ultimate load.

The failure of short compression members owing to ultimate load is governed by the strength of the materials and the size of the $\mathrm{C} / \mathrm{S}$. In the case of a long column, however, slenderness, which causes extra bending moments owing to lateral deformation or buckling, has the most significant impact on ultimate load capacity. Depending on the slenderness ratio and end restraint circumstances, a slender column may fail due to material failure or stability failure [42, 43]. The material strength is wholly used in material loss, but the member becomes unstable due to significant lateral displacement in the case of stability failure.

2.5.2. Test Specimens. The experimental work consisted of testing fourteen columns, of which seven were short and seven were long columns. All short columns cast were of dimension $100 \times 100 \times 1000 \mathrm{~mm}$ square in $\mathrm{C} / \mathrm{S}$, and all long columns cast were of dimension $100 \times 100 \times 1500 \mathrm{~mm}$ square in C/S [44]. For both long and short columns, the primary bar reinforcement was $12 \mathrm{~mm}$ in diameter, with lateral ties of $8 \mathrm{~mm}$ diameter at spacing of $50 \mathrm{~mm}$ at both ends and $100 \mathrm{~mm}$ at middle portions as per IS 456-2000. The axial load capacity of these column 


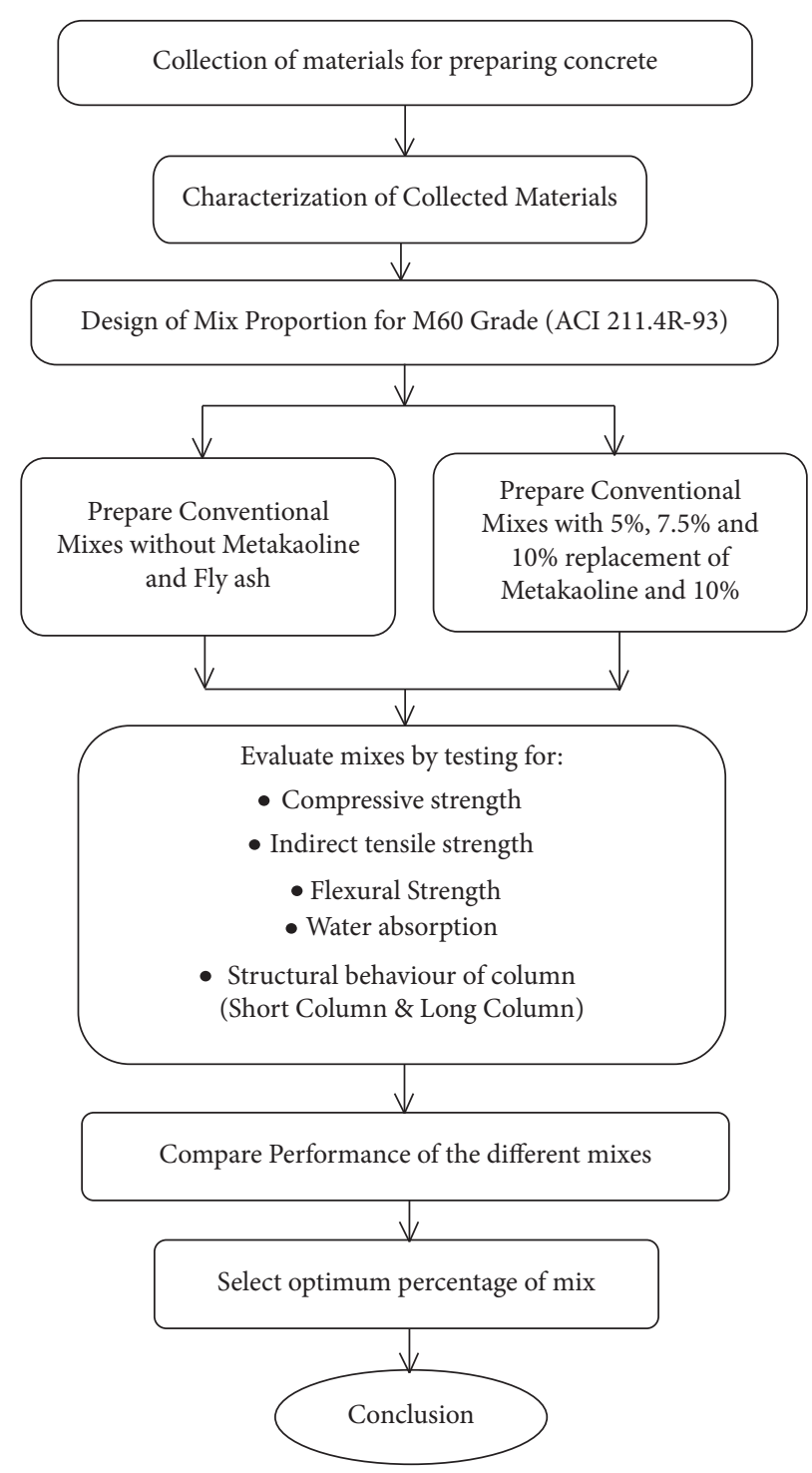

FIGURE 3: Methodology adopted in the study.

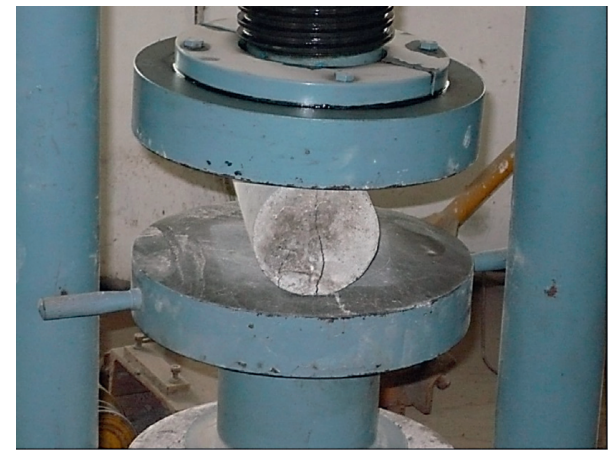

FIgURE 4: Failure of the cylinder specimen.

specimens and details of the specimens were arrived at based on the procedure given in IS 456-2000. The end condition of columns was hinged at both ends, and it was achieved by resting the columns over a neoprene pad. Figure 6 illustrates the reinforcement details of short and long columns.
2.5.3. Test Procedure. A hydraulic jack of $500 \mathrm{kN}$ was used for this axial loading test. The applied axial loads were measured with an electronic load cell $500 \mathrm{kN}$ and monitored with a load indicator. To ensure a hinge condition, the axial force was passed through the steel plate onto the column. The column specimens are adapted to correspond with the columns in the centerline of the axial load.

The loads were applied as axial for short columns, and the axial deformations were determined on all four sides, in the middle of the specimen. The average load-versus axial deformation curves have been considered. The intermediate height deflection of the short column specimen received from the electronic displays was measured by a $50 \mathrm{~mm}$ linear voltage differential transducer (LVDT).

The load was applied as axial for both short and long columns with a minimum eccentricity of $0.05 \mathrm{D}$ deformations that were measured at both tension and compression faces. The deflections were measured on one column face at the head, center, and foot [45]. 


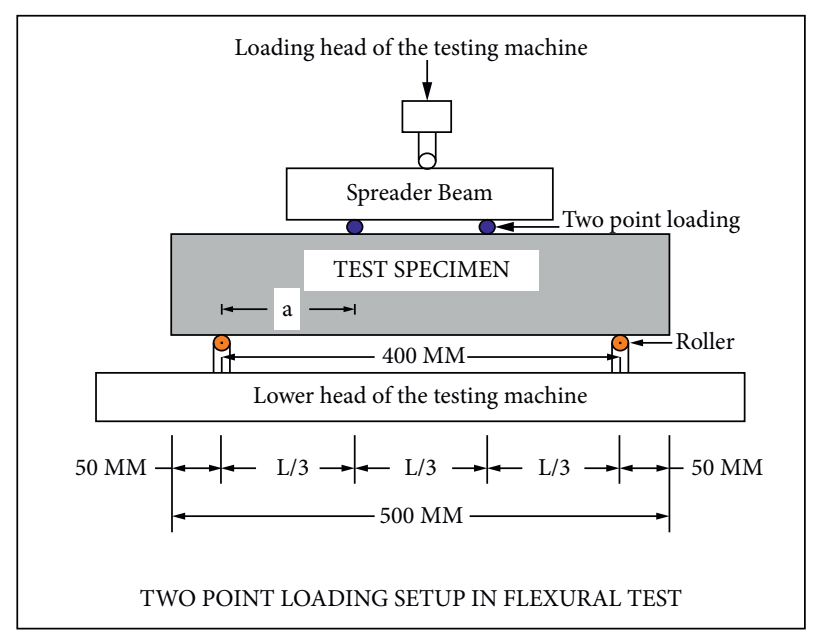

FIgURE 5: Two-point loading setup in flexure test.



FiguRe 6: Reinforcement details.

The load was gradually applied, and the deflection was monitored at regular intervals at various load stages. At the same time, strain values were also measured, and observations of crack start and propagation at multiple loading locations, ultimate load to failure, and mechanism of failure were taken. Figure 7 illustrates a typical test setup.

\section{Results and Discussion}

3.1. Compressive Strength Test. The test results reveal the CS of different mixtures MR1, MR2, MR3, MR4, MR5, MR6, and MR7 at ages 3, 7, 28, 56, and 90 days. Concrete strength improves significantly because of the high pozzolanic activity that forms surplus calcium silicate hydrate (CSH) gel when metakaolin is used as an extra additive. Mix MR6 (which includes 7.5 percent metakaolin and $10 \%$ fly ash) had 28 days of maximum cube strength of $64 \mathrm{MPa}$, whereas mix MR3 (which contains 7.5 percent metakaolin) had 28-day full cube strength of $59 \mathrm{MPa}$.

Metakaolin concrete has a lot of reactive silica, which gives it good strength. The substitution level and the curing age are the two criteria that determine the increase in concrete cube strength when combined with metakaolin. At 28 days, the HPC exhibits a greater upturn in compressive strength than conventional concrete specimens. Figure 8 compares compressive strength for various mixtures.

3.2. Split Tensile Strength Test. For several combinations, the STS differs from 4.99 to $6.37 \mathrm{~N} / \mathrm{mm}^{2}$ at the age of 28 days.
Mix MR6, 7.5\% metakaolin, and 10\% fly ash have been shown to have greater tensile strength. For MR6 mix, the ultimate split tensile strength by 28 days from $6.37 \mathrm{MPa}$ is achieved. The comparison for the split tensile strength in the various combinations is illustrated in Figure 9.

3.3. Flexural Strength Test. Flexural strength ranges between 4.59 to $6.05 \mathrm{MPa}$ at 28 days for varied mixtures (MR1 to MR7). The MR6 mix, which contains 7.5 percent metakaolin and 10\% fly ash, has greater flexural strength than the other mixes, with maximum 28-day strength of 6.05 $\mathrm{MPa}$. In this test, we achieved a flexural strength of 6.05 MPa for MR6, higher than the code's recommended value. Figure 10 depicts the fluctuation in flexural strength after 28 days.

\subsection{Durability Studies}

3.4.1. Water Absorption. The maximum water absorption value found for MR1 is 3.89 percent. The mix MR7 has the least water absorption rate of 1.39 percent when contrasted near the conventional concrete mix.

The concrete's porosity decreases when mineral admixture is added, which is the major reason for the fall in water absorption. Mineral additives, like metakaolin and fly ash, provide a porous microstructure in the concrete mixes, which improves its durability. Figure 11 depicts the percentage variation in water absorption. 


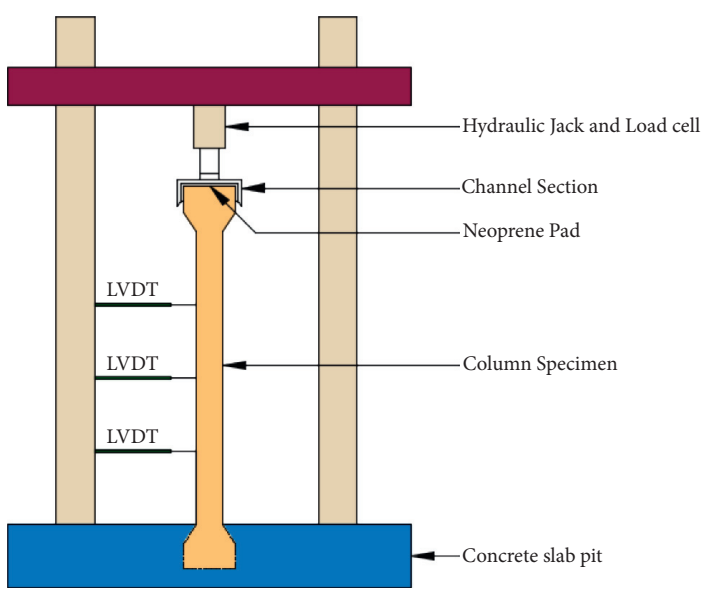

Figure 7: Experimental test set up for column.



FIGURE 8: Variation of compressive strength at various ages.

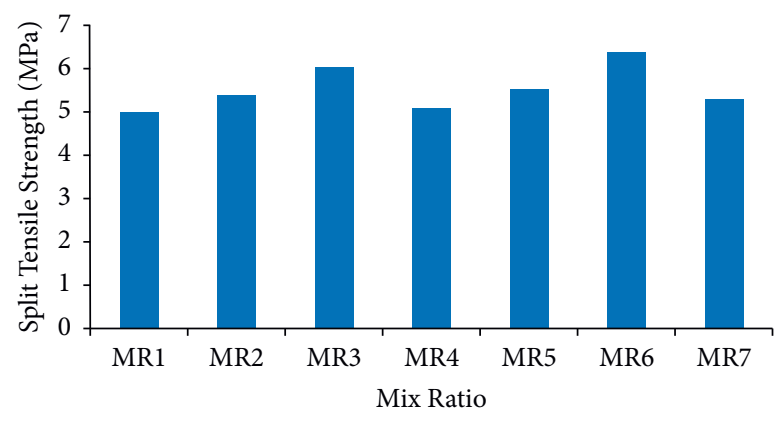

Figure 9: Comparison of the tensile strength.

\subsection{Structural Behaviour of the Column}

\subsubsection{Short Column}

(1) Conventional Specimen: Short Column (MR1). The MR1 was the first specimen to be tested. $25 \mathrm{kN}$ increments gently increased the vertical load. The initial crack occurred at the column top when the load reached $164 \mathrm{kN}$. The pops expanded also spread nearby the original pop as the load increased. The conventional column's maximum load was $196 \mathrm{kN}$. When it also failed at the top of the column due to concrete crush, it made a loud explosion.

(2) Short Columns Using Partial Replacement of MK and FA (SCMK and SCMKFA). While vertically loaded beneath the loading component, the MK substituted specimens MR2, 


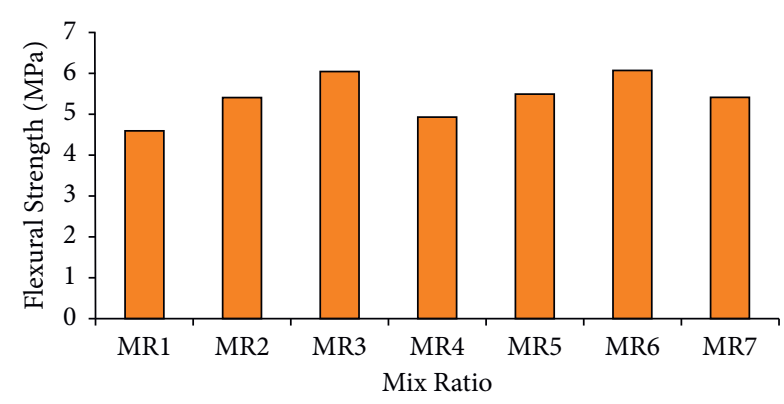

口 28 Days

Figure 10: Comparison of the flexural strength.

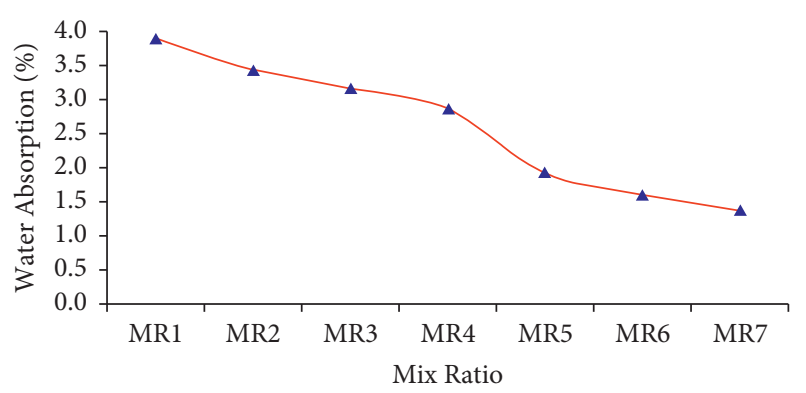

Figure 11: Percentage variation of water absorption.

MR3, MR4, MR5, MR6, and MR7 exhibited similar behaviour. All of the columns collapsed under compression due to either crushing the concrete core or vertical reinforcement bending. The ultimate load reached by MR3, MR6, and MR7 collapsed at loads of $252 \mathrm{kN}, 249 \mathrm{kN}, 263 \mathrm{kN}$, and $258 \mathrm{kN}$ correspondingly. MR6 obtained the highest ultimate load of $263 \mathrm{kN}$. Figure 12 indicates the load against axial deformation curves for SCMK and SCMKFA. Figure 13 depicts the failure pattern of the HPC short column.

\subsection{Long Column}

3.6.1. Conventional Specimen (MR1). In the conventional MR1, the first sample was cast using standard concrete. The vertical load was gradually transmitted in $25 \mathrm{kN}$ intervals. The first failure was on the column head when the load was $174 \mathrm{kN}$. As the load improved, the pops spread about the first crack. For the control column, the ultimate load was $198 \mathrm{kN}$, and the failure was caused by the crushed concrete on the head of the column.

When loaded axially under the loading frame, the MK replaced the columns MR2, MR3, and MR4 displayed identical behaviour. On the basis of the column, all columns collapsed and formed vertical and diagonal cracks over the portion or crushed the concrete inner portion due to the bending of the vertical reinforcing. The maximum load for MR3 was $234 \mathrm{KN}$. The ultimate load increases were $18.18 \%$. The remaining specimens show $4.55 \%$ increase compared to the reference specimen. When compared to control columns, the column samples MR5, MR6, and MR7 were futile at loads of $228 \mathrm{kN}, 254 \mathrm{kN}$, and $226 \mathrm{kN}$, respectively, which are 15.15 percent, 28.28 percent, and 14.14 percent higher.

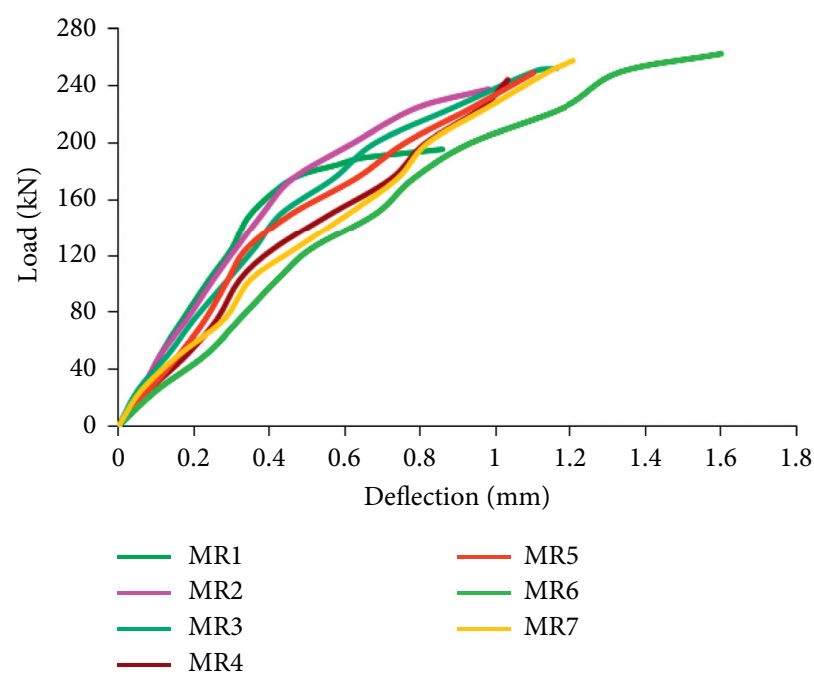

FIGURE 12: Load-deflection curves for SCMK and SCMKFA.

Figure 14 illustrates the load-deflection characteristics. Figure 15 depicts the failure patterns in HPC long columns.

3.6.2. Mode Deflection Values for Long Columns. Figure 16 depicts the modes of deflection of long columns under various loads. Regardless of column length, the trends remained consistent. In Figure 16, smooth curve lines were used to create fitted sine half-wave curves. Depending on the slenderness ratio, the measured deformation was near the sine line. The deflection curve is represented using

$$
w=w_{m} \sin \left(\frac{\pi H}{L}\right),
$$

where $w$ denotes the column deformation, $w_{m}$ denotes the column middle deformation value, $H$ represents the column height from the base to the computation location, and $L$ denotes the total length of the column.

3.6.3. Moment versus Rotation $(M-\Theta)$. The curvature $(\phi)$ for the intermediate $\mathrm{C} / \mathrm{S}$ may be represented using (6) as follows:

$$
\Phi=\frac{1}{\rho}=\frac{\pi^{2} w}{L^{2}} .
$$

The curvature radius is $\rho$, and the middle lateral deflection is $w$.

Moment versus rotation curves for the column specimen were tested for axial compression and uniaxial bending. Comparison of $(\mathrm{M}-\theta)$ curves for columns specimens MR1 to MR7 is depicted in Figure 17.

The moment curvature is influenced by the slenderness ratio as seen in Figure 17. It is apparent that depending on the length of the column, all specimens progressed through three stages: elastic, elastic-plastic, and cracking. The results are quite consistent, especially when it comes to elastic responsiveness. All specimens broke abruptly after reaching peak loads, and load values dropped rapidly. 


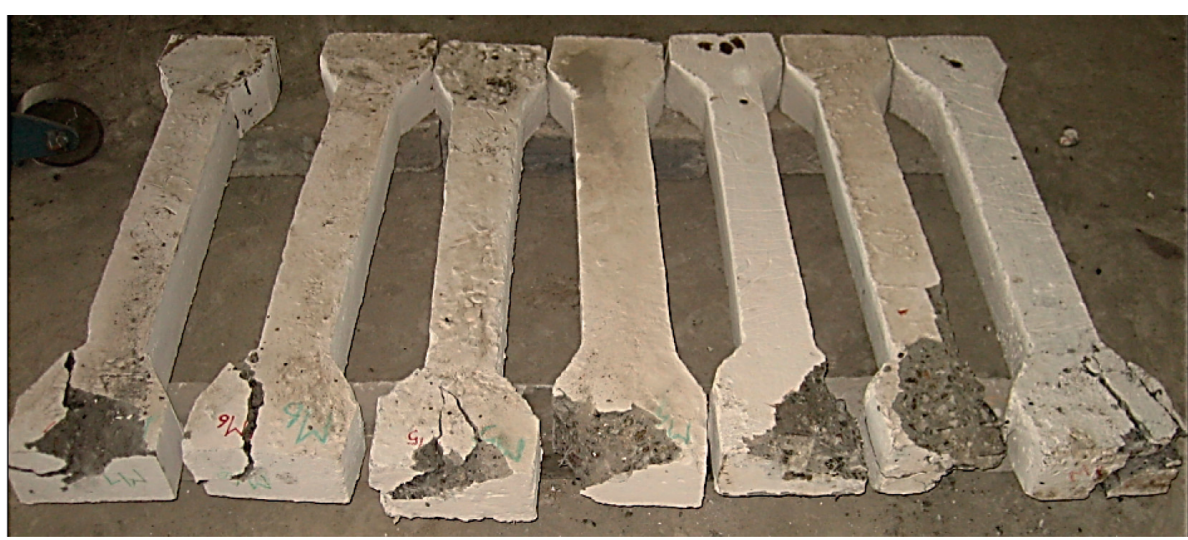

FIGURE 13: Short column specimens after testing.

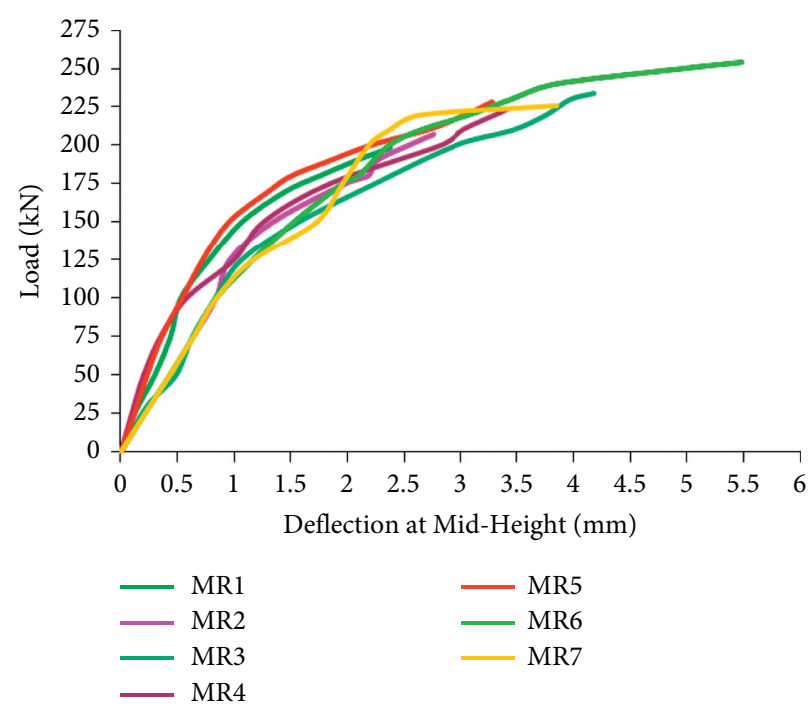

Figure 14: Load deflection at midheight curves for LCMK and LCMKFA.

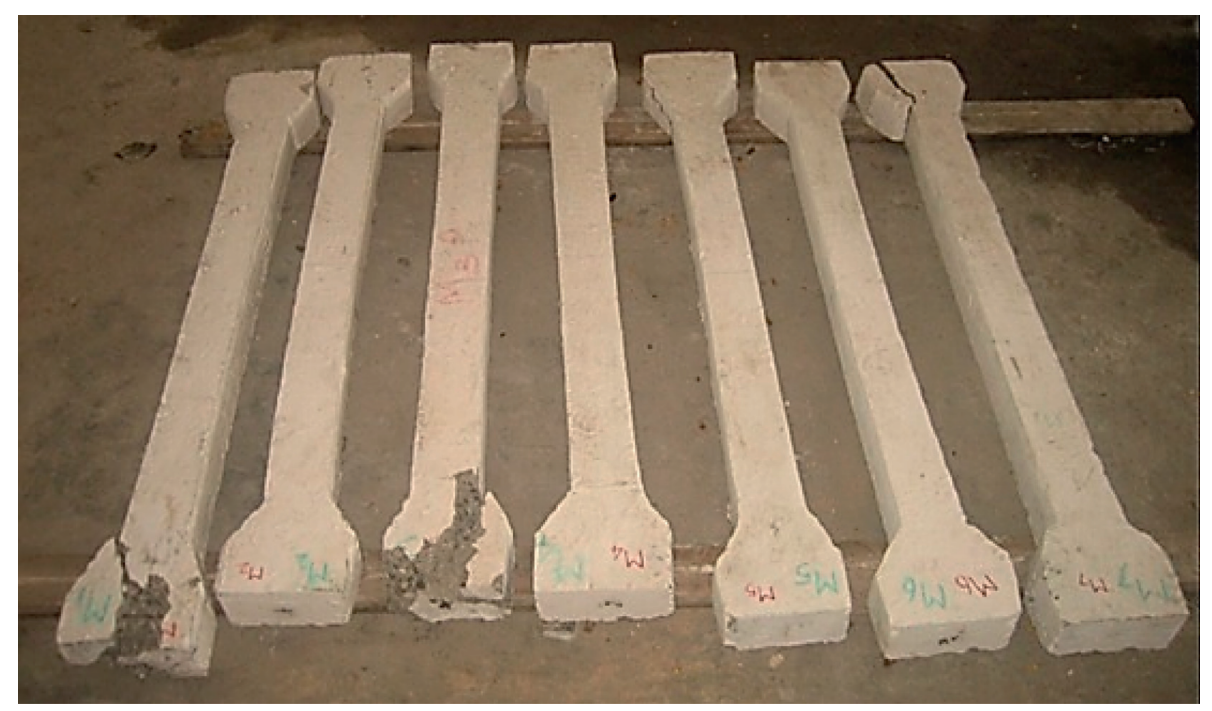

FIGURE 15: Long column specimens after testing. 


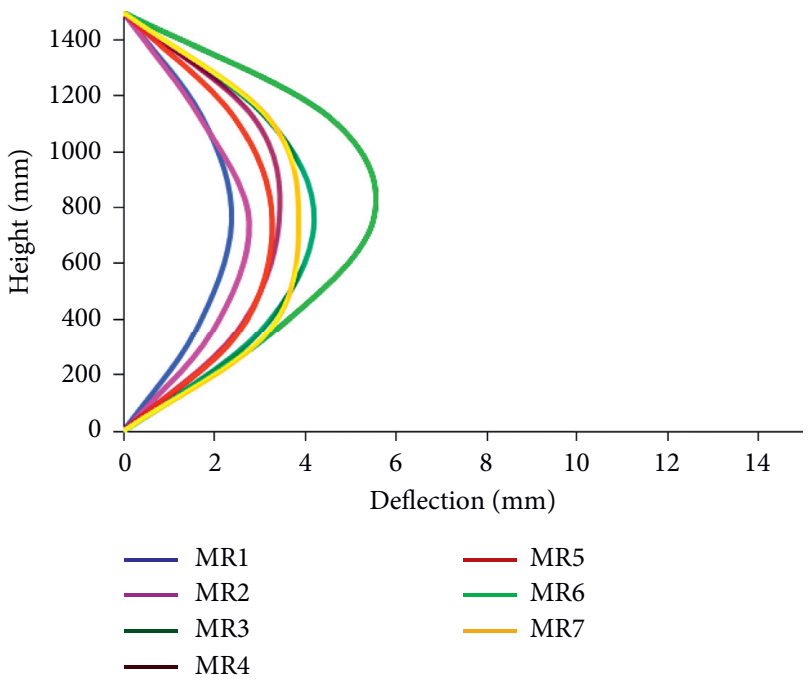

FIGURE 16: Mode deflection shapes of LC.

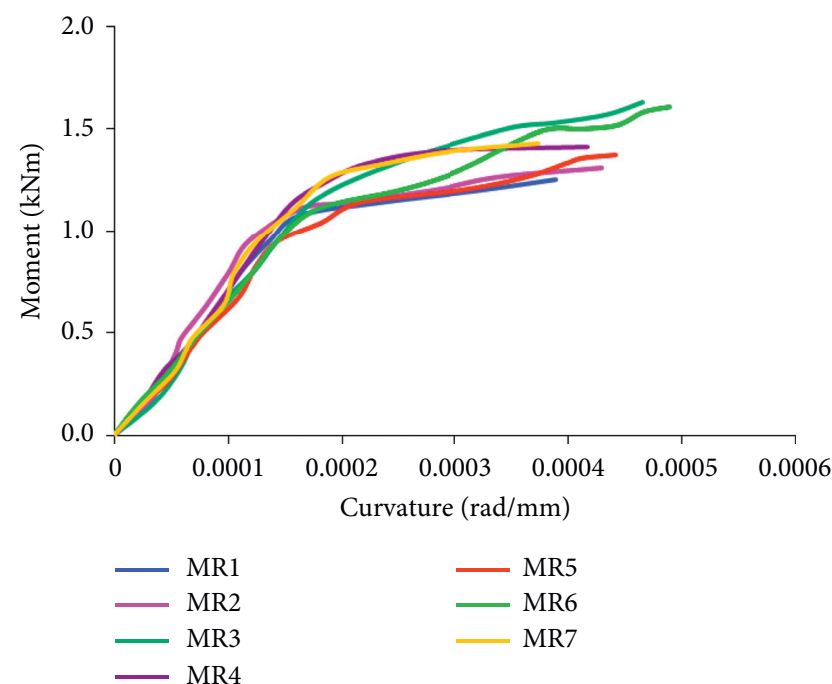

FIgURE 17: Moment curvature characteristics for LCMK and LCMKFA.

\section{Conclusion}

This research looked at the effect of cementitious materials on the mechanical properties of HPC in detail. The following is an overview of the results of the numerous investigations:

(i) In the current invention, M60 mix designs have been developed as per ACI standard for HPC employing metakaolin and fly ash and superplasticizer. The results highlight that the cementitious properties, that is, reactions and filler properties of metakaolin, lead to higher strength development for the design specimens.

(ii) Fresh concrete properties show higher cohesiveness and are less prone to segregation due to the presence of fly ash and metakaolin. (iii) The optimal proportion of MR3 mix arrived with 7.5 percentage of metakaolin and zero percentage of fly ash shows higher resistance to compressive strength. Compared to fly ash concrete, metakaolin concrete has a higher early strength.

(iv) For the combined effect of metakaolin with 7.5 percent and fly ash with 10 percent, the MR6 mix shows $7.34 \%$ higher compressive strength than the reference concrete. The CS shows an increase in trends with an increase in curing days. Mineral additives, like fly ash and metakaolin, provide a coarser microstructure in the concrete mixes, which improves its durability in addition. The compression (cube) failure pattern of concrete is caused by coarse aggregate crushing rather than bond failure.

(v) According to the cube and cylinder test results, the percentage of water absorption of the HPC mixes, including metakaolin and fly ash, was lower when compared to the controlled mixes (without metakaolin and fly ash).

(vi) Due to concrete crushing with an explosive bang, the HPC short columns collapsed. With an influence in admixture \%, the load-carrying ability of the SC improved. MR3 achieved a maximum ultimate load of $263 \mathrm{kN}$, which is 34.9 percent less than the predicted load.

(vii) For HPC, long columns displayed splash damage of the concrete cover and buckling with a progressive load but finally broke owing to concrete crushing in the compression area. For the long column, MR6 achieved an ultimate load of $254 \mathrm{kN}$, which is roughly 31.1 percent less than the hypothetical ultimate load.

(viii) The failure of the columns resulted in all of them deteriorating due to a crack and crushing of the concrete in their heads and bases.

So the replacement of $7.5 \%$ of metakaolin and $10 \%$ of fly ash is generally useful for better strength values in M60 grade of concrete.

\section{Data Availability}

The data used to support the findings of this study are included in the paper.

\section{Conflicts of Interest}

The authors declare that there are no conflicts of interest regarding the publication of this paper.

\section{Acknowledgments}

This project was funded by the Researchers Supporting Project (no. RSP2021/405), King Saud University, Riyadh, Saudi Arabia. 


\section{References}

[1] P. F. Alessandro and J. N. Daria, "Supplementary cementitious materials in concrete, part I," Materials, vol. 14, 2021.

[2] R. Dharmaraj, "Mechanical properties of high performance concrete incorporating rice husk ash," Indian Journal of Applied Research, vol. 6, no. 6, pp. 19-21, 2015.

[3] D. Singh, R. Chaudhary, and A. Karthick, "Review on the progress of building-applied/integrated photovoltaic system," Environmental Science and Pollution Research, vol. 28, no. 35, Article ID 47689, 2021.

[4] M. Narmatha and K. T. Felix, "High performance concrete using metakaoline and fly ash with partial replacement of cement," International Journal of Applied Engineering Research, vol. 9, no. 23, Article ID 19541, 2015.

[5] S. U. Kannan, "Experimental investigation on high performance concrete using silica fume and fly ash," International Journal of Engineering Research and Development, vol. 13, no. 10, pp. 42-49, 2017.

[6] V. N. Tailor, C. D. Patel, and B. R. Patel, "Experimental study of high performance concrete using portland pozzolana cement with silica fume and replacing natural river sand with quarry dust," International Research Journal of Engineering and Technology (IRJET), vol. 5, no. 4, pp. 3119-3123, 2018.

[7] T. Sathish, S. Tharmalingam, V. Mohanavel et al., "Weldability investigation and optimization of process variables for TIG-welded aluminium alloy (AA 8006)," Advances in Materials Science and Engineering, vol. 2021, Article ID 2816338, 17 pages, 2021.

[8] A. Elahi, P. Basheer, S. Nanukuttan, and Q. Khan, "Mechanical and durability properties of high performance concretes containing supplementary cementitious materials," Construction and Building Materials, vol. 24, no. 3, pp. 292299, 2010.

[9] K. Alagar and S. Thirumal, "Standalone PV-Wind-DG-Battery hybrid energy system for zero energy buildings in smart city coimbatore, India," in Advanced Controllers for Smart CitiesSpringer, Berlin, Germany, 2021.

[10] B. Patil and P. Kumbhar, "Strength and durability properties of high performance concrete incorporating high reactivity metakaolin," International Journal of Modern Engineering Research, vol. 2, no. 3, pp. 1099-1104, 2012.

[11] G. Aliakbar, H. Reza, E. M. Julie, V. Thomas, and K. Minoru, "Experimental investigation of the performance of concrete columns strengthened with fiber reinforced concrete jacket," Construction and Building Materials, vol. 194, pp. 51-61, 2019.

[12] A. Karthick, V. K. Chinnaiyan, J. Karpagam, V. S. Chandrika, and P. R. Kumar, "Optimization of PV-wind hybrid renewable energy system for health care buildings in smart city," Hybrid Renewable Energy Systems, Wiley, New Jersey, NY, USA, 2021.

[13] K. Khorramian and P. Sadeghian, "Experimental investigation of short and slender rectangular concrete columns reinforced with GFRP bars under eccentric axial loads," Journal of Composites for Construction, vol. 24, no. 6, Article ID 04020072, 2020.

[14] T. Raja, V. Mohanavel, T. Sathish et al., "Thermal and flame retardant behavior of neem and banyan fibers when reinforced with a bran particulate epoxy hybrid composite," Polymers, vol. 13, no. 22, 2021.

[15] N. Mahesh and R. Dharmaraj, "Behaviour of cold-formed built-up closed section with web stiffener under axial compression," International Journal of Advances in Engineering \& Technology, vol. 1, no. 3, pp. 68-72, 2018.
[16] P. Swetha and P. E. Sakaria, "An experimental investigation on axial strength of steel tubular short columns infilled with high volume GGBS," International Journal of Scientific and Research Publications, vol. 5, no. 10, pp. 1-8, 2015.

[17] S. Sebastin, A. K. Priya, A. Karthick, R. Sathyamurthy, and A. Ghosh, "Agro waste sugarcane bagasse as a cementitious material for reactive powder concrete," Cleanroom Technology, vol. 2, no. 4, pp. 476-491, 2020.

[18] S. W. Yoo, "compression behavior of confined columns with high-volume fly ash concrete," Advances in Materials Science and Engineering, vol. 2017, 2017.

[19] R. Dharmaraj, S. Gopikumar, P. Ebby Darnay et al., "Appraisal of green construction material by optimizing the strength of tannery sludge concrete," IOP Conference Series: Materials Science and Engineering, vol. 1145, no. 1, pp. 1-7, 2021.

[20] M. Abedini, E. A. Khlaghi, J. Mehrmashhadi, M. H. Mussa, M. Ansari, and T. Momeni, "Large deflection behavior effect in reinforced concrete columns exposed to extreme dynamic loads," engrXiv, vol. 14, p. 32, 2019.

[21] G. H. Ahmed, H. Ahmed, B. Ali, and R. Alyousef, "Assessment of high performance self-consolidating concrete through an experimental and analytical multi-parameter approach," Materials, vol. 14, p. 985, 2021.

[22] B. Sabharinadh and V. Ranga Rao, "Flexural behavior of highperformance reinforced concrete beams," International Journal of Recent Technology and Engineering, vol. 7, no. 6C2, pp. 334-340, 2019.

[23] J. Zhang, Y. Zhao, and H. Li, "Experimental investigation and prediction of compressive strength of ultra-high performance concrete containing supplementary cementitious materials," Advances in Materials Science and Engineering, vol. 2017, Article ID 4563164, 8 pages, 2017.

[24] K. J. Brahma Chari and V. Ranga Rao, "The experimental investigation of concrete with various supplementary cementitious materials and glass fiber," International Journal of Scientific \& Technology Research, vol. 9, no. 3, pp. 5290-5295, 2020.

[25] S. R. Kumar, K. S. Amiya, and K. S. R. Dilip, “An experimental study on the compressive strength of alccofine with silica fume based concrete," Applied Mechanics and Materials, vol. 857, pp. 36-40, 2016.

[26] V. Malagavelli and P. Rao, "High performance concrete with GGBS and robo sand," International Journal of Engineering Science and Technology, vol. 2, no. 10, pp. 5107-5113, 2010.

[27] N. K. karthikeyan, R. Dharmaraj, and V. Deepika, "Experimental study on concrete by partial replacement of solid plastics and granite powder," International Journal of Innovative Research in Science, Engineering and Technology, vol. 7, no. Spl.5, pp. 434-441, 2018.

[28] S. Muralikrishnan and T. Felix Kala, "Experimental investigation on high performance concrete of using manufactured sand as fine aggregate," International Journal of Applied Engineering Research, India, vol. 6, pp. 15643-15649, 2015.

[29] M. Qureshi, Y. Tandel, and B. Patel, "An experimental study on high strength concrete using fly ash and alccofine," Journal of Structural Engineering, vol. 2, no. 4, pp. 1-9, 2014.

[30] R. Dharmaraj, S. Anandaraj, N. Sanjivnalan, S. S. Kumar, N. Shivash, and S. Srisharan, "Turkey berries leaves extract as corrosion inhibitor embedded steel in concrete," IOP Conference Series: Materials Science and Engineering, vol. 1145, no. 1, pp. 1-8, 2021.

[31] S. Mahdi, "Experimental investigation on the effect of cementitious materials on fresh and mechanical properties of 
self-consolidating concrete," Advances in Concrete Construction, vol. 8, no. 3, pp. 225-237, 2019.

[32] S. C. R. Kumar, R. Anuradha, and R. Dharmaraj, "Numerical investigation on ultra-high performance concrete beam under pure bending," Resources Policy, vol. 74, Article ID 101046, 2017.

[33] H. I. Owamah, S. C. Ikpeseni, R. Dharmaraj et al., "Influence of diethanolamine on the properties of concrete, corrosion rate of rebar and renewable energy generation," Arabian Journal for Science and Engineering, 2021, in Press.

[34] P. Dinakar, P. K. Sahoo, and G. Sriram, "Effect of metakaolin content on the properties of high strength concrete," Int $J$ Concr Struct Mater, vol. 7, pp. 215-223, 2013.

[35] A. Camoes, P. Rocha, and S. Jalali, "High performance concrete using flyash," in Proceedings of the 3th International Conference, 2002.

[36] Aci 211.4R, Guide for Selecting Proportions for High Strength concrete Using Portland Cement and Other Cementitious Materials, ACI Committee, Farming-ton Hills, Michigan, 2008.

[37] R. M. R. Dharmaraj, "Effect of corrosion on mechanical and durability properties of reinforced self compacting concrete," Middle-East Journal of Scientific Research, vol. 24, no. 8, pp. 2609-2615, 2016.

[38] P. C. Basu, "High performance concrete," in Proceedings INAE National Seminar on Engineered Building Materials and Their Performance, 2003.

[39] G. I. R. Dharmaraj, "Study on strength and durability properties of concrete with metakaolin," Transactions on Innovations in Science \& Technology, vol. 1, no. 4, pp. 12-15, 2016.

[40] A. Suvarna, P. J. Salunke, and N. G. Gore, "Silica fume and ground granulated blast furnace slag as cement replacement in fiber reinforced concrete," International Research Journal of Engineering and Technology, vol. 2, pp. 438-443, 2015.

[41] E. Etman, N. Kassem, A. Ahmed, and H. Ahmed, "Behavior of high performance concrete columns subjected to eccentric load," in Proceedings of the International Conference on Advances in Structural and Geotechnical Engineering ICASGE, Hurghada, Egypt, March 2017.

[42] W. A. Waryosh, M. M. Rasheed, and A. M. Alaa Haider, "Experimental study of reinforced concrete columns strengthened with CFRP under eccentric loading," Journal of Engineering and Development, vol. 16, no. 3, 2012.

[43] A. A. Khalil and D. R. Maulan, "Behavior of reinforced concrete slender columns under short-term repeated loading," in Proceedings of the First Engineering Conference, vol. III, pp. 210-223, Mansoura, Egypt, 1995.

[44] I. K. Wasan, N. G. Ikbal, and R. M. Zeinab, "Behavior of high performance fiber reinforced," ARPN Journal of Engineering and Applied Sciences, vol. 7, no. 11, pp. 1455-1467, 2012.

[45] J. Xu, C. Wu, H. Xiang et al., "Behaviour of ultra high performance fibre reinforced concrete columns subjected to blast loading," Engineering Structures, vol. 118, pp. 97-107, 2016. 